\title{
Applicability of graded prognostic assessment of lung cancer using molecular markers to lung adenocarcinoma patients with brain metastases
}

\author{
Hongwei $\mathrm{Li}^{1, *}$, Jianhong Lian ${ }^{2}$, Songyan Han ${ }^{3, *}$, Weili Wang ${ }^{1}$, Haixia Jia ${ }^{1}$, Jianzhong \\ $\mathrm{CaO}^{1}$, Xiaqin Zhang ${ }^{1}$, Xin Song ${ }^{1}$, Sufang $\mathrm{Jia}^{1}$, Jiwei Ren ${ }^{5}$, Weihua Yang ${ }^{3}$, Yanfeng \\ $\mathbf{X i}^{4}$ and Shengmin Lan ${ }^{1}$ \\ ${ }^{1}$ Department of Radiation Oncology, Shanxi Provincial Cancer Hospital, Shanxi Medical University, Taiyuan, Shanxi Province \\ 030013, People's Republic of China \\ ${ }^{2}$ Department of Surgery, Shanxi Provincial Cancer Hospital, Shanxi Medical University, Taiyuan, Shanxi Province 030013, \\ People's Republic of China \\ ${ }^{3}$ Department of Chemotherapy, Shanxi Provincial Cancer Hospital, Shanxi Medical University, Taiyuan, Shanxi Province \\ 030013, People's Republic of China \\ ${ }^{4}$ Department of Pathology, Shanxi Provincial Cancer Hospital, Shanxi Medical University, Taiyuan, Shanxi Province 030013, \\ People's Republic of China \\ ${ }^{5}$ Department of Medical Imageology, Shanxi Provincial Cancer Hospital, Shanxi Medical University, Taiyuan, Shanxi Province \\ 030013, People's Republic of China \\ *These authors have contributed equally to this work \\ Correspondence to: Hongwei Li, email: 3420010@163.com
}

Jianhong Lian, email: 438129230@qq.com

Keywords: lung cancer, adenocarcinoma, brain metastass, gene alterations, prognosis

Received: February 28, $2017 \quad$ Accepted: July 11, $2017 \quad$ Published: August 07, 2017

Copyright: Li et al. This is an open-access article distributed under the terms of the Creative Commons Attribution License 3.0 (CC BY 3.0), which permits unrestricted use, distribution, and reproduction in any medium, provided the original author and source are credited.

\section{ABSTRACT}

Several scoring systems are available to estimate prognosis and assist in selecting treatment methods for non-small cell lung cancer (NSCLC) patients with brain metastasis, including recursive partitioning analysis (RPA), basic score for brain metastases (BSBM), and diagnosis-specific graded prognostic assessment (DS-GPA). Lung-molGPA is an update of the DS-GPA that incorporates EGFR and/or ALK mutation status. The present study tested the applicability of these four indexes in 361 lung adenocarcinoma patients with brain metastasis. Potential predictive factors in our independent multivariate analysis included patient age, Karnofsky performance status, EGFR and ALK mutation status, and use of targeted therapy. In the log-rank test, all four systems predicted overall survival $(O S)(P<0.001)$. Harrell's $C$ indexes were $0.732,0.724,0.729$, and 0.747 for RPA, BS-BM, DS-GPA, and Lung-molGPA, respectively. Our results confirmed that the Lung-molGPA index was useful for estimating OS in our patient cohort, and appeared to provide the most accurate predictions. However, the independent prognostic factors identified in our study were not entirely in agreement with the Lung-molGPA factors. In an era of targeted therapy, Lung-molGPA must be further updated to incorporate more specific prognostic factors based on additional patient data.

\section{INTRODUCTION}

Brain metastases are among the leading causes of morbidity and mortality in patients with non-small cell lung cancer (NSCLC) [1]. Brain metastasis (BM) risk in NSCLC is $40 \%$ over the course of the disease $[2,3]$. The prognosis for patients with $\mathrm{BMs}$ is generally poor; without treatment, median survival is estimated at 1-2 months. 
With whole brain radiotherapy (WBRT), the standard treatment for BMs regardless of histological subtype, median survival is $4-6$ months $[4,5]$. Several prognostic scoring systems based on independent prognostic factors have been developed to evaluate pretreatment variable contributions, help in selecting the appropriate treatment for individual patients, and guide future research. Widely accepted prognostic systems include, Recursive Partitioning Analysis (RPA), Basic Score for Brain Metastases (BS-BM), and the Graded Prognostic Assessment Index (GPA) [6-8]. However, prognostic factors vary with cancer type and histological subtype. Many cancers that commonly result in BMs, including NSCLC, small-cell lung cancer, breast cancer, melanoma, and renal carcinoma, involve different prognostic factors. Accordingly, Sperduto, et al. developed a diagnosisspecific prognostic factors index (DS-GPA) [9]. The NSCLC GPA includes age, Karnofsky performance status (KPS), extracranial metastases, and number of BMs. Although the DS-GPA stratified patients with BMs by primary site and highlighted characteristics of tumors that metastasize to the brain, the various primary tumor genotypes did not fit within the prognostic classification system. Additionally, gene alterations were also important prognostic factors for BMs [10-13].

Prognoses of lung adenocarcinoma patients with BMs are often associated with gene mutation status, including mutations in the epidermal growth factor receptor (EGFR), anaplastic lymphoma kinase-rearranged (ALK), and V-Ki-ras2 Kirsten rat sarcoma viral oncogene homolog (kRAS) [10, 14, 15]. To further refine the NSCLC-specific GPA, a new prognostic system, LungmolGPA, was proposed based on 2,186 NSCLC patients with BMs. This new system included not only age, KPS, extracranial metastases, and number of BMs, but also EGFR and ALK mutation status $[16,17]$.

The present study reappraised the new LungmolGPA index to determine its applicability in a Chinese patient cohort. The resultant scores were compared with those from three other published prognostic systems (RPA, BS-BM, DS-GPA), and predictive values were assessed.

\section{RESULTS}

\section{Patient characteristics and treatment}

By the end of the follow-up period for the 361 patients diagnosed with BMs from lung adenocarcinoma, $160(44.3 \%)$ had confirmed EGFR mutations and 10 (2.8\%) had ALK mutations; one patient had both. Pretreatment patient demographics are shown in Table 1. Patients were predominantly male $(52.6 \%)$ and nonsmokers $(56.8 \%)$. Median age at diagnosis was 57 years (range, 28-80). Most patients (75.9\%) presented with a KPS $>70$. More than half of the patients had $\geq 2$ brain lesions. Approximately $73.4 \%$ had uncontrolled primary tumors and $61.8 \%$ presented with extracranial metastases. In total, 107 patients $(29.6 \%)$ were treated with radiotherapy only (77 patients with WBRT, 20 with SRS, and 10 with SRS plus WBRT), 71 (19.7\%) received an EGFR-TKI or ALK-TKI only $(76.1 \%$ of these had EGFR or ALK mutations), and 55 (15.2\%) were treated with RT plus an EGFR-TKI (EGFR-TKI concurrently or sequentially with radiotherapy). The remaining 63 patients received chemotherapy. Sixty-five patients received steroid treatment or best supportive care.

\section{Overall survival and prognoses}

At the last follow-up in January 2017, 112 patients (31.0\%) were still alive. Median survival time was 11.3 months (95\% CI: 9.596-13.004), and one-year survival rate was $46.9 \%$. Potential OS predictive factors are shown in Table 2. In univariate analyses, pretreatment prognostic factors predicting better OS included female gender, age $<65$ years, EGFR or ALK mutation, high KPS, and no extracranial metastases. However, only female gender was significant $(P=0.055)$. Of the various treatments, EGFRTKIs resulted in the best OS (Figure 1). In multivariate analyses, OS predictive factors included age, EGFR or ALK status, KPS, and targeted therapy.

\section{Prognostic indexes}

Prognostic values for all four indexes are shown in Figure 2 and Table 3. In the log-rank test, all four indexes predicted OS $(P<0.001)$. Harrell's $C$ indexes were 0.732 , $0.729,0.724$, and 0.747 for RPA, DS-GPA, BS-BM, and Lung-molGPA, respectively. All four systems appeared to offer medium predictive values, with Lung-molGPA performing best.

\section{DISCUSSION}

Prognostic indexes are important tools for estimating prognosis and tailoring treatments for individual patients with BMs. Such indexes are usually established by summing the prognostic weights of independent factors in Cox regression models and then dividing these into risk zones. However, independent prognostic factors vary depending on the primary tumor site, and other biological makers may also play roles. The recently published NSCLC-specific Lung-molGPA index is the first to incorporate both traditional factors, such as patient age and gender, and EGFR and ALK mutation status [16, 17]. Our assessment showed that the Lung-molGPA index offers medium OS predictive ability in lung adenocarcinoma patients with BMs.

In our study, all four of the published prognostic indexes assessed could predict patient prognosis, demonstrating the reliability and clinical relevance of these scores. However, the Lung-molGPA is the first 
Table 1: Basic demographics

\begin{tabular}{|c|c|c|}
\hline Variable & Number of patients & $\%$ \\
\hline \multicolumn{3}{|l|}{ Gender } \\
\hline Male & 190 & 52.6 \\
\hline Female & 171 & 47.4 \\
\hline \multicolumn{3}{|l|}{ Age(years) } \\
\hline median(range) & & \\
\hline \multicolumn{3}{|l|}{ KPS } \\
\hline$<70$ & 87 & 24.1 \\
\hline $70-80$ & 235 & 65.1 \\
\hline $90-100$ & 39 & 10.8 \\
\hline \multicolumn{3}{|l|}{ Smoking history } \\
\hline Never & 205 & 56.8 \\
\hline Ever & 156 & 43.2 \\
\hline \multicolumn{3}{|l|}{ KRAS } \\
\hline Positive & 7 & 1.9 \\
\hline Negative & 107 & 29.6 \\
\hline unknown & 247 & 68.4 \\
\hline \multicolumn{3}{|l|}{ ALK } \\
\hline Positive & 10 & 2.8 \\
\hline Negative & 96 & 26.6 \\
\hline unknown & 255 & 70.6 \\
\hline \multicolumn{3}{|l|}{ EGFR } \\
\hline Positive & 160 & 44.3 \\
\hline Negative & 201 & 55.7 \\
\hline \multicolumn{3}{|c|}{ NO. of brain metastases } \\
\hline 1 & 131 & 36.3 \\
\hline 2 & 74 & 20.5 \\
\hline 3 & 32 & 8.9 \\
\hline 4 & 49 & 13.6 \\
\hline$\geq 5$ & 75 & 20.8 \\
\hline \multicolumn{3}{|c|}{ Extracranial metastases } \\
\hline Yes & 223 & 61.8 \\
\hline No & 138 & 38.2 \\
\hline \multicolumn{3}{|c|}{ Control of primary tumor } \\
\hline Yes & 96 & 26.6 \\
\hline No & 265 & 73.4 \\
\hline \multicolumn{3}{|c|}{ WBRT/SRS/WBRT+SRS } \\
\hline Yes & 162 & 44.9 \\
\hline No & 199 & 55.1 \\
\hline
\end{tabular}




\begin{tabular}{lcc}
\hline Variable & Number of patients & \% \\
\hline TKIs & & \\
Yes & 126 & 34.9 \\
No & 235 & 65.1 \\
Chemotherapy & & \\
Yes & 63 & 17.5 \\
No & 298 & 82.5 \\
\hline
\end{tabular}

KPS, Karnofsky performance status; KRAS, V-Ki-ras2 Kirsten rat sarcoma viral oncogene homolog; ALK, anaplastic lymphoma kinase-rearranged; EGFR, epidermal growth factor receptor; WBRT, whole brain radiotherapy; SRS, stereotactic radiosurgery; TKIs, tyrosine kinase inhibitors.

Table 2: Results of the univariate and multivariate analysis of survival

\begin{tabular}{|c|c|c|c|c|}
\hline \multirow[t]{2}{*}{ Variables } & \multirow{2}{*}{$\frac{\text { Univariate analysis }}{\mathbf{P}}$} & \multicolumn{3}{|c|}{ Multivariate analysis } \\
\hline & & Risk ratio & $95 \% \mathrm{CI}$ & $\mathbf{P}$ \\
\hline Gender & 0.055 & & & \\
\hline \multicolumn{5}{|l|}{ Female vs. male } \\
\hline Age & 0.048 & 0.703 & 0.523 to 0.945 & 0.02 \\
\hline \multicolumn{5}{|l|}{$\geq 65$ vs. $<65$} \\
\hline Gene status & $<0.001$ & 0.692 & 0.519 to 0.922 & 0.012 \\
\hline \multicolumn{5}{|l|}{$\begin{array}{l}\text { EGFR pos or ALK } \\
\text { pos }\end{array}$} \\
\hline \multicolumn{5}{|l|}{$\begin{array}{l}\text { EGFR neg and ALK } \\
\text { neg/unk }\end{array}$} \\
\hline $\begin{array}{l}\text { Karnofsky } \\
\text { Performance Score }\end{array}$ & $<0.001$ & 0.065 & 0.040 to 0.105 & $<0.001$ \\
\hline \multicolumn{5}{|l|}{$\begin{array}{l}<70 \text { vs. } 70-80 \text { vs. } \\
90-100\end{array}$} \\
\hline $\begin{array}{l}\text { Extracranial } \\
\text { metastases }\end{array}$ & 0.017 & & & \\
\hline \multicolumn{5}{|l|}{ Yes vs. no } \\
\hline TKIs & $<0.001$ & 0.718 & 0.527 to 0.978 & 0.036 \\
\hline Yes vs. no & & & & \\
\hline
\end{tabular}

EGFR, epidermal growth factor receptor; ALK, anaplastic lymphoma kinase-rearranged; TKIs, tyrosine kinase inhibitors; $\mathrm{CI}$, confidence interval.

prognostic system, updated from the lung-DS-GPA, that includes potential biomarker statuses. Harrell's concordance indexes ranged from $0.724-0.747$ (medium predictive ability) for the four indexes, with the LungmolGPA performing best.

However, multivariate analysis results in the present study did not totally agree with those of Sperduto, et al. [16]. Independent pretreatment prognostic factors in the Cox regression model were KPS, EGFR and ALK status, and age. In our study, number of metastases and control of primary tumor, which are included in the Lung-molGPA index, were not significant. We suggest three possible reasons for these discrepancies. First, treatments in the present study differed from those in the study by Sperduto, et al., in which all BM patients were treated with WBRT or SRS. In our study, $34.9 \%$ of patients received targeted therapy, which systematically treated both cranial and extracranial lesions [18]. Therefore, number of metastases 
and control of primary tumor might not appear significant in our multivariate analysis. Targeted therapy is now widely recognized as the first-line treatment for patients with EGFR mutations [19-21], and radiotherapy appears to offer these patients no survival benefit $[22,23]$. Our study also showed that EGFR-TKI treatment alone was the most effective of the options evaluated via log-rank test. Our multivariate analysis, which included both pretreatment and treatment factors, showed that both gene mutation status and targeted therapy could predict prognosis.

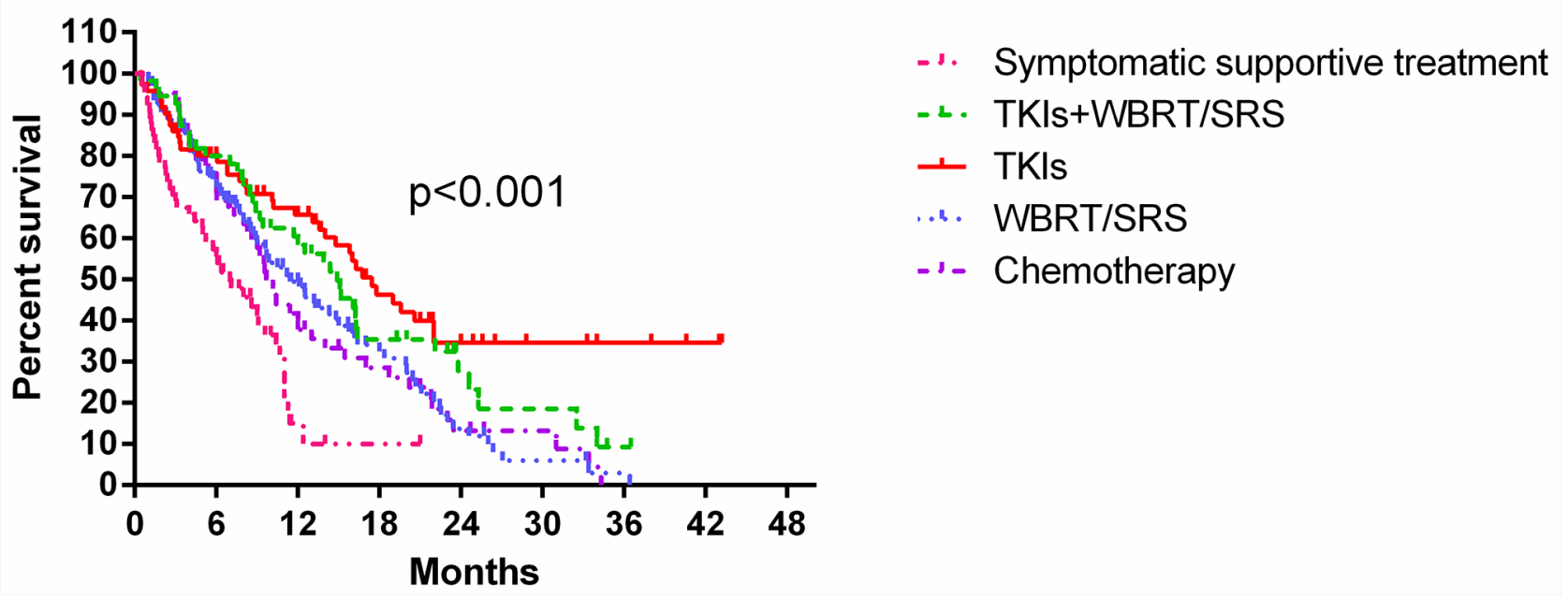

Figure 1: Kaplan-Meier curves showing OS by treatment modality.
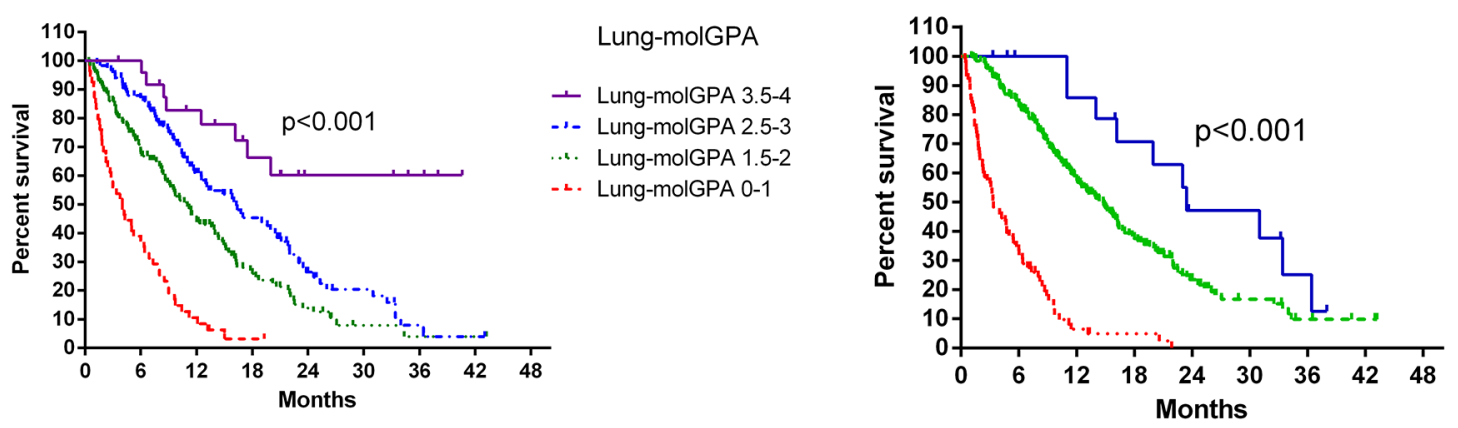

RPA

... RPA 3

- ᄂ. RPA 2

- RPA 1
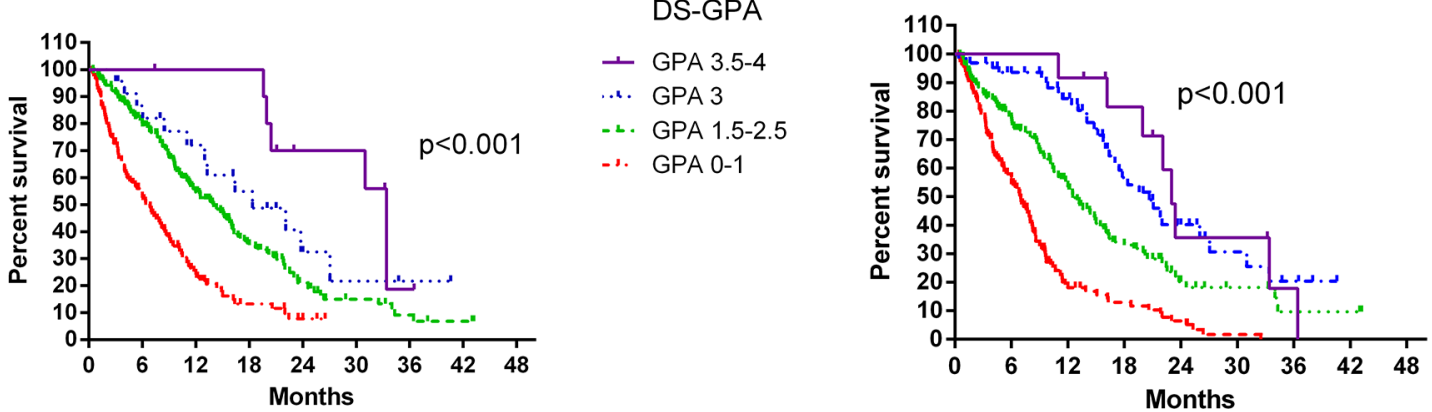

BSBM

- BSBM 3

- - BSBM 2

… BSBM 1

- ᄂ. BSBM 0

Figure 2: OS according to each of the four studied indexes. 
Table 3: Distribution of the study population and median overall survival according to the class of prognostic scores; Harrell's concordance index (HCS)

\begin{tabular}{|c|c|c|c|c|c|}
\hline & $\begin{array}{c}\text { Number of pts } \\
(\%)\end{array}$ & $\operatorname{MOS}(95 \% \mathrm{CI})$ & $\mathbf{P}$ & $\begin{array}{c}\text { Harard ratio }(95 \% \\
\text { CI) }\end{array}$ & HCS $(95 \%$ CI) \\
\hline RPA & & & & & $0.732(0.691-0.772)$ \\
\hline 1 & $17(4.7)$ & 23.44M (10.889-35.991) & & 1 & \\
\hline 2 & $257(71.2)$ & $14.8 \mathrm{M}(12.62-16.98)$ & $<0.001$ & $1.945(1.021-3.705)$ & \\
\hline 3 & $87(24.1)$ & $3.37 \mathrm{M}(2.276-4.464)$ & & $10.185(5.136-20.195)$ & \\
\hline DS-GPA & & & & & $0.729(0.689-0.770)$ \\
\hline $3.5-4$ & $11(3.0)$ & $33.4 \mathrm{M}(31.35-35.45)$ & & 1 & \\
\hline 3 & $23(6.4)$ & $18.37 \mathrm{M}(8.458-28.282)$ & $<0.001$ & $1.776(0.673-4.684)$ & \\
\hline $1.5-2.5$ & $206(57.1)$ & $14 \mathrm{M}(11.454-16.546)$ & & $2.784(1.221-6.348)$ & \\
\hline $0-1$ & $121(33.5)$ & $6.4 \mathrm{M}(4.727-8.073)$ & & $6.230(2.692-14.414)$ & \\
\hline BSBM & & & & & $0.724(0.684-0.764)$ \\
\hline 3 & $12(3.3)$ & $23 \mathrm{M}(21.16-24.84)$ & & 1 & \\
\hline 2 & $63(17.5)$ & $20.67 \mathrm{M}(16.245-25.095)$ & & $1.044(0.480-2.274)$ & \\
\hline 1 & $145(40.2)$ & $12.53 \mathrm{M}(10.376-14.684)$ & $<0.001$ & $2.084(1.009-4.306)$ & \\
\hline 0 & $141(39.1)$ & $7 \mathrm{M}(5.641-8.359)$ & & $4.887(2.363-10.110)$ & \\
\hline Lung-molGPA & & & & & $0.747(0.706-0.787)$ \\
\hline $3.5-4$ & $25(6.9)$ & $17 \mathrm{M}$ & & 1 & \\
\hline $2.5-3$ & $117(32.4)$ & $16.3 \mathrm{M}(11.229-21.371)$ & $<0.001$ & $2.907(1.396-6.055)$ & \\
\hline $1.5-2$ & $165(45.7)$ & $11 \mathrm{M}(9.208-12.792)$ & & $4.629(2.243-9.551)$ & \\
\hline $0-1$ & $54(15)$ & $4 \mathrm{M}(2.441-5.559)$ & & $14.138(6.571-30.418)$ & \\
\hline
\end{tabular}

CI, confidence interval; MOS, median overall survival; M, months; Pts, patients.

This confirms the need to incorporate gene statuses into prognostic indexes for lung adenocarcinoma patients with BMs.

Second, due to EGFR mutation variations between Chinese and western patients, the present study had a higher EGFR mutation rate than the Sperduto, et al. study $(44.3 \%$ vs. 29\%) [24, 25]. Thus, more patients in our study were treated with EGFR-TKIs, potentially impacting our results. Finally, Sperduto, et al. reported that only $54 \%$ of patients $(816 / 1,521)$ had confirmed EGFR and/or ALK alternations. This finding might have reduced the weight of gene alterations and thus affected Cox regression analysis results. Our findings suggest that identification of novel independent pretreatment prognostic factors would increase NSCLC BM patient prognostic index accuracies.

Our study had several limitations. Initially, only 106 patients had been tested with ALK mutations status.
This may underscore the effects of this gene alteration in multivariate analysis. Additionally, the number of nonadenocarcinoma NSCLC patients with gene mutations was small, and this subgroup was not studied. The EGFR mutation rate in patients without adenocarcinoma of the lung is $<5 \%$ [26]. In our study, $11 / 47$ non-adenocarcinoma patients with BMs $(23.4 \%)$ had EGFR mutations. A specific prognostic system for this patient subgroup is needed.

In conclusion, we confirmed that the Lung-molGPA index could be useful in estimating OS in patients with BMs from lung adenocarcinoma. The Lung-molGPA appeared to offer the most accurate predictions of the four systems assessed. However, the independent prognostic factors found in our study did not entirely match those of the Lung-molGPA index. In the era of targeted therapy, this index must be further updated to incorporate more specific prognostic factors based on additional patient data. 
Table 4: Clinical parameters used for 4 prognostic indexs (RPA, DS-GPA, BSBM, and Lung-molGPA)

\section{RPA}

\begin{tabular}{|c|c|c|c|}
\hline Class 1 & \multicolumn{3}{|c|}{ Age $<65$ y, KPS $\geq 70$, controlled primary tumor, no extracranial metastases } \\
\hline Class 2 & \multicolumn{3}{|l|}{ All patients not in Class 1 or 3} \\
\hline Class 3 & \multicolumn{3}{|l|}{$\mathrm{KPS}<70$} \\
\hline \multicolumn{4}{|c|}{ DS-GPA } \\
\hline & 0 & 0.5 & 1 \\
\hline Age,y & $>60$ & $50-59$ & $<50$ \\
\hline KPS & $<70$ & $70-80$ & $90-100$ \\
\hline Number of BM & $>3$ & $2-3$ & 1 \\
\hline \multirow[t]{3}{*}{ ECM } & Yes & & No \\
\hline & \multicolumn{3}{|l|}{ BSBM } \\
\hline & 0 & & 1 \\
\hline KPS & $50-70$ & & $80-100$ \\
\hline Control of primary tumor & No & & Yes \\
\hline \multirow[t]{3}{*}{ ECM } & Yes & & No \\
\hline & \multicolumn{3}{|l|}{ Lung-molGPA } \\
\hline & 0 & 0.5 & 1 \\
\hline Age,y & $\geq 70$ & $<70$ & \\
\hline KPS & $<70$ & $70-80$ & $90-100$ \\
\hline $\mathrm{ECM}$ & Yes & & No \\
\hline Number of BM & $>4$ & $1-4$ & \\
\hline Gene status & EGFR neg/unk and ALK neg/unk & & EGFR pos or ALK pos \\
\hline
\end{tabular}

RPA, recursive partitioning analysis; DS-GPA, diagnosis-specific graded partitioning analysis; BSBM, basic score for brain metastases; BM, brain metastases; KPS, Karnofsky performance status.

\section{MATERIALS AND METHODS}

\section{Patient eligibility}

A total of 2,823 patients with NSCLC and EGFR mutations were identified between January 2010 and August 2016 from our lung cancer medical database. All EGFR mutations were identified by direct DNA sequencing or amplification refractory mutation system (ARMS). Some patients were also tested for ALK mutations by polymerase chain reaction (PCR) or immunohistochemical (IHC) staining. Patients selected for this study had been diagnosed with lung adenocarcinoma and BMs via computed tomography (CT) and/or magnetic resonance imaging (MRI) at diagnosis or during the course of treatment. Patients with synchronous lung cancer and other cancers were excluded. Patient clinical and treatment data, follow-up examination results, and/or date of death were available. As a result, 408 patients were diagnosed with BMs. Thirty-one patients with squamous cell lung cancer, six with neuroendocrine carcinoma, four with small cell lung cancer, two with synchronous lung cancer and esophageal carcinoma, one with breast cancer, and one with cervical cancer were excluded from the study. Two additional patients were excluded due to incomplete clinical data. In total, 361 patients met the selection criteria. Patient-related variables included age, gender, KPS, primary lesion status (controlled vs. uncontrolled), extracranial systemic metastases (present or absent), number of BMs (single vs. multiple), gene mutation status (EGFR- or ALK-positive vs. EGFR-negative and ALKnegative/unknown). Treatment options included WBRT, stereotactic radiosurgery (SRS), management with EGFRTKIs (tyrosine kinase inhibitors; gefitinib or erlotinib), chemotherapy, and targeted therapy and radiotherapy combined. The Institutional Review Board of Shanxi Cancer Hospital approved the study.

The primary endpoint of this study was overall survival (OS), defined from the date of BM diagnosis to death or last follow-up. OS and prognostic factors were 
evaluated in uni- and multivariate analyses. Patients were stratified according to RPA, DS-GPA, and BS-BM criteria separately. RPA, GPA, BS-BM, and NSCLC-specific GPA parameters are shown in Table 4. Differences between the systems and their predictive values were evaluated.

\section{Statistical analysis}

OS was estimated from the first day of BM diagnosis to death or date of last follow-up using the Kaplan-Meier method. Subgroup analysis was performed using the logrank test for univariate analyses and the Cox proportional hazards model for multivariate analyses. $P<0.05$ was considered significant. Harrell's $C$ index was used to estimate the discriminative abilities of the four indexes. All analyses were performed using SPSS statistical software 17.0 and R v. 2.15.2 [27].

\section{ACKNOWLEDGMENTS}

We thank LetPub (www.letpub.com) for linguistic assistance during the preparation of this manuscript.

\section{CONFLICTS OF INTEREST}

The authors declare that they have no conflicts of interest.

\section{GRANT SUPPORT}

This work was funded by the Wu Jieping Medical Foundation (320.6750.12693) and is a Research Project Supported by the Health and Family Planning Commission of Shanxi Province Scholarship in China (2015052).

\section{REFERENCES}

1. Torre LA, Bray F, Siegel RL, Ferlay J, Lortet-Tieulent J, Jemal A. Global cancer statistics, 2012. CA Cancer J Clin. 2015; 65:87-108.

2. Barnholtz-Sloan JS, Sloan AE, Davis FG, Vigneau FD, Lai $\mathrm{P}$, Sawaya RE. Incidence proportions of brain metastases in patients diagnosed (1973 to 2001) in the Metropolitan Detroit Cancer Surveillance System. J Clin Oncol. 2004; 22:2865-72

3. Nayak L, Lee EQ, Wen PY. Epidemiology of brain metastases. Curr Oncol Rep. 2012; 14:48-54.

4. Gaspar LE, Mehta MP, Patchell RA, Burri SH, Robinson PD, Morris RE, Ammirati M, Andrews DW, Asher AL, Cobbs CS, Kondziolka D, Linskey ME, Loeffler JS, et al. The role of whole brain radiation therapy in the management of newly diagnosed brain metastases: a systematic review and evidence-based clinical practice guideline. J Neurooncol. 2010; 96:17-32.

5. Patil CG, Pricola K, Sarmiento JM, Garg SK, Bryant A, Black KL. Whole brain radiation therapy (WBRT) alone versus WBRT and radiosurgery for the treatment of brain metastases. Cochrane Database Syst Rev. 2012; 12:CD006121

6. Gaspar L, Scott C, Rotman M, Asbell S, Phillips T, Wasserman T, McKenna WG, Byhardt R. Recursive partitioning analysis (RPA) of prognostic factors in three Radiation Therapy Oncology Group (RTOG) brain metastases trials. Int J Radiat Oncol Biol Phys. 1997; 37:745-51.

7. Lorenzoni J, Devriendt D, Massager N, David P, Ruíz S, Vanderlinden B, Van Houtte P, Brotchi J, Levivier M. Radiosurgery for treatment of brain metastases: estimation of patient eligibility using three stratification systems. Int $\mathrm{J}$ Radiat Oncol Biol Phys. 2004; 60:218-24.

8. Sperduto PW, Berkey B, Gaspar LE, Mehta M, Curran W. A new prognostic index and comparison to three other indices for patients with brain metastases: an analysis of 1,960 patients in the RTOG database. Int J Radiat Oncol Biol Phys. 2008; 70:510-4.

9. Sperduto PW, Chao ST, Sneed PK, Luo X, Suh J, Roberge D, Bhatt A, Jensen AW, Brown PD, Shih H, Kirkpatrick J, Schwer A, Gaspar LE, et al. Diagnosis-specific prognostic factors, indexes, and treatment outcomes for patients with newly diagnosed brain metastases: a multi-institutional analysis of 4,259 patients. Int J Radiat Oncol Biol Phys. 2010; 77:655-61.

10. Hsiao SH, Lin HC, Chou YT, Lin SE, Kuo CC, Yu MC, Chung CL. Impact of epidermal growth factor receptor mutations on intracranial treatment response and survival after brain metastases in lung adenocarcinoma patients. Lung Cancer. 2013; 81:455-4.

11. Lee HL, Chung TS, Ting LL, Tsai JT, Chen SW, Chiou JF, Leung HW, Liu HE. EGFR mutations are associated with favorable intracranial response and progression-free survival following brain irradiation in non-small cell lung cancer patients with brain metastases. Radiat Oncol. 2012; $7: 181$.

12. Subbiah IM, Lei X, Weinberg JS, Sulman EP, ChavezMacGregor M, Tripathy D, Gupta R, Varma A, Chouhan J, Guevarra RP, Valero V, Gilbert MR, Gonzalez-Angulo AM. Validation and development of a modified breast graded prognostic assessment as a tool for survival in patients with breast cancer and brain metastases. J Clin Oncol. 2015; 33:2235-45.

13. Le Scodan R, Massard C, Jouanneau L, Coussy F, Gutierrez M, Kirova Y, Lerebours F, Labib A, Mouret-Fourme E. Brain metastases from breast cancer: proposition of new prognostic score including molecular subtypes and treatment. J Neurooncol. 2012; 106:169-76.

14. Johung KL, Yeh $\mathrm{N}$, Desai NB, Williams TM, Lautenschlaeger T, Arvold ND, Ning MS, Attia A, Lovly CM, Goldberg S, Beal K, Yu JB, Kavanagh BD, et al. Extended survival and prognostic factors for patients with ALK-rearranged non-small cell lung cancer and brain metastasis. J Clin Oncol. 2016; 34:123-9. 
15. Tomasini P, Serdjebi C, Khobta N, Metellus P, Ouafik L, Nanni I, Greillier L, Loundou A, Fina F, Mascaux C, Barlesi F. EGFR and KRAS mutations predict the incidence and outcome of brain metastases in non-small cell lung cancer. Int J Mol Sci. 2016; 18:17.

16. Sperduto PW, Yang TJ, Beal K, Sperduto PW, Yang TJ, Beal K, Pan H, Brown PD, Bangdiwala A, Shanley R, Yeh $\mathrm{N}$, Gaspar LE, Braunstein S, et al. Estimating survival in patients with lung cancer and brain metastases an update of the graded prognostic assessment for lung cancer using molecular markers(lung-molGPA). JAMA Oncol. 2017; 3:827-31.

17. Sperduto PW, Yang TJ, Beal K, Pan H, Brown PD, Bangdiwala A, Shanley R, Yeh N, Gaspar LE, Braunstein S, Sneed P, Boyle J, Kirkpatrick JP, et al. The effect of gene alterations and tyrosinekinase inhibitionon survival and cause of death in patients with adenocarcinoma of the lung and brain metastases. Int J Radiat Oncol Biol Phys. 2016; 96:406-13.

18. Dempke WC, Edvardsen K, Lu S, Reinmuth N, Reck M, Inoue A. Brain metastases in NSCLC - are TKIs changing the treatment strategy? Anticancer Res. 2015; 35:5797-806.

19. Kim JE, Lee DH, Choi Y, Yoon DH, Kim SW, Suh C, Lee JS. Epidermal growth factor receptor tyrosine kinase inhibitors as a first-line therapy for never-smokers with adenocarcinoma of the lung having asymptomatic synchronous brain metastasis. Lung Cancer. 2009; 65:351-4.

20. Wu YL, Zhou C, Cheng Y, Lu S, Chen GY, Huang C, Huang YS, Yan HH, Ren S, Liu Y, Yang JJ. Erlotinib as secondline treatment in patients with advanced non-small-cell lung cancer and asymptomatic brain metastases: a phase II study (CTONG-0803). Ann Oncol. 2013; 24:993-9.
21. Lilenbaum RA, Horn LA. Management of EGFR mutationpositive non-small cell lung cancer. J Natl Compr Canc Netw. 2016; 14:672-4.

22. Byeon S, Ham JS, Sun JM, Lee SH, Ahn JS, Park K, Ahn MJ. Analysis of the benefit of sequential cranial radiotherapy in patients with EGFR mutant non-small cell lung cancer and brain metastasis. Med Oncol. 2016; 33:97.

23. Jiang T, Su C, Li X, Zhao C, Zhou F, Ren S, Zhou C, Zhang J. EGFR TKIs plus WBRT demonstrated no survival benefit other than that of TKIs alone in patients with NSCLC and EGFR mutation and brain metastases. J Thorac Oncol. 2016; 11:1718-28.

24. Shi Y, Li J, Zhang S, Wang M, Yang S, Li N, Wu G, Liu W, Liao G, Cai K, Chen L, Zheng M, Yu P, et al. Molecular epidemiology of EGFR mutations in Asian patients with advanced non-small-cell lung cancer of adenocarcinoma histology - Mainland China Subset Analysis of the PIONEER study. PLoS One. 2015; 10:e0143515.

25. Arrieta O, Cardona AF, Martín C, Más-López L, Corrales-Rodríguez L, Bramuglia G, Castillo-Fernandez O, Meyerson M, Amieva-Rivera E, Campos-Parra AD, Carranza H, Gómez de la Torre JC, Powazniak Y, et al. Updated frequency of EGFR and KRAS mutations in nonsmall-cell lung cancer in Latin America: the LatinAmerican Consortium for the Investigation of Lung Cancer (CLICaP). J Thorac Oncol. 2015; 10:838-43.

26. Kenmotsu H, Serizawa M, Koh Y, Isaka M, Takahashi T, Taira T, Ono A, Maniwa T, Takahashi S, Mori K, Endo M, Abe M, Hayashi I, et al. Prospective genetic profiling of squamous cell lung cancer and adenosquamous carcinoma in Japanese patients by multitarget assays. BMC Cancer. 2014; 14:786.

27. R Core Team 2013. R Foundation for Statistical Computing, Vienna, Austria. 